\title{
Multicast, Hierarchical and Fast Handover in Mobile Ipv6 Wireless Network: A Test- Bed Experience
}

\begin{abstract}
Mobile IPv6 (MIPv6) allows mobile devices to be always addressed by its home address. This paper describes a micro-mobility based test-bed development with enhanced mobile IPv6 features including multicast function and hierarchical design. The test-bed is hardware and software based comprising of five Personal Computers (PCs) and one laptop. The laptop represents the Mobile Node (MN) while the functions of the PCs are as follows; two as Access Points (AP), one as Home Agent (HA), and the other two as Foreign Multicast Router $(\mathrm{MR})$ and Correspondent Node $(\mathrm{CN})$ respectively. This test-bed is used to analyze handover delay, packet delay, packet loss, throughput and overall throughput in real wireless environment for conventional handover and enhanced mobile IPv6 handover scenarios. The results show the enhanced handover scheme reduces handover delay $94.32 \%(4.35 \mathrm{~s}$ to $0.2 \mathrm{~s}$ ), packet delay by $84.43 \%(0.7 \mathrm{~s}$ to $0.109 \mathrm{~s})$, packet loss from 44 to zero packet while the throughput and overall throughput were increased by approximately $117.34 \%$ and $124.3 \%$ respectively over the conventional system. Finally, it can be concluded that the proposed scheme gives advantages of higher throughput, zero packet loss and lower delays and can significantly improve micro mobility performance of $3 \mathrm{G}, 4 \mathrm{G}$ and beyond mobile communication systems.
\end{abstract}

Keyword: Mobile IPv6, wireless, handover, multicast, test-bed 